\title{
Educational practice to strengthen clinical medicine students' humanistic quality
}

\author{
Xiaona Guo, Liu Yang \\ Huanghe Science and Technology University, Zhengzhou Henan, 450063, China
}

Keywords: Clinical medicine, Humanistic quality education, Practice.

\begin{abstract}
The transition of modern medical model has increasingly highlighted the humanistic spirit of medical science. Strengthening the humanistic quality education of clinical medical students is the only way for medical educational reform and development of health service. Through analysis on the current status of medical humanistic quality education, reasons and necessity for intensification, this article has conducted exploration and practice on the educational path.
\end{abstract}

\section{Introduction}

Medical science is a kind of cultural phenomenon or cultural subject, as well as the ecological philosophy of mind [1]. Medical humanity and humanistic return is the inevitable result of medical development. Medical humanity include the sub-scope of medical humanities such as humanistic belief, medical objective, medical nursing, humanistic care, and doctor-patient communication. The assignment of advanced medical education is to adapt to social development, cultivate high-quality modern medical talents with noble character and proficient business. How to strengthen clinical medical students' humanistic quality, and cultivate medical talents for comprehensive development is a challenge in front of medical education.

\section{Status and reason of medical humanistic quality education}

Clinical medical student is medical practitioner in the future. It is the integration of medical technology and service concept for them to cure diseases and at the same time to care and respect patients, focus on their psychological factors and living and social environment. Humanistic quality is an important quality of medical students but the current situation is not optimistic: single knowledge level structure, lack of humanistic knowledge reserve, lack of lack of humanistic knowledge foundation. For their ability, they cannot adapt to the requirements of actual medical work, poor application ability of language and words, poor communicative competence and adaptability, and lack of innovative ability, etc. For their self-accomplishment, secularization of their behaviors and speeches, and vulgarization of cultural taste. This article tries to explore the crucial reasons of the separation between medical science and humanity by taking following aspects into consideration:

\section{Colleges, teachers and students all emphasize this issue}

Colleges are mostly in the imbalanced status of "valuing profession but ignoring humanities" in teaching concept, teaching mode, course setting and students' evaluation aspect. Medical education is in the same condition. While stressing professional study, humanities course teaching has been relevantly reduced and set as courses without examination under loose management. Instructors should be equipped with abundant medical knowledge and profound humanistic connotations. But currently compound type teachers are very few. The teaching contents are tedious and effect is very poor, which has influenced teachers' initiative and activity. In addition, medical students are usually from science classes which under emphasize humanistic courses so that it has prevented their language competence, writing ability, recognition ability, social ability and comprehensive quality from improving, thus result in the situation of "teachers do not like giving lectures and students do not like listening”. 


\section{Humanistic course setting is out of balance.}

Ideological and political education with "two classes" as the core has played a positive role for establishing students' moral education and three views, it is poor in humanity and lack of professional pertinence. Other humanistic course class and period have been compressed correspondingly, accounting for about $8 \%$ of the total credit hours [3].

\section{Medical humanistic education theory and practice are disconnected}

In medical ethics, medical psychology, health law, doctor-patient communication, medical sociology and other course study, the teaching contents originate from clinical practice, students lack enough understanding of real medical environment in their leaning stage and feel unfamiliar with the instructed contents, lack the practice of direct communication with patients, and ignore the experience required for medical humanistic education so that the instruction effect cannot achieve the expected target. In clinical practice stage when they are closely exposed to patients, they lack purposeful guidance from relevant courses.

\section{The necessity of strengthening medical humanistic education}

\section{The development requirement of new medical mode}

People's requirements for health are changing with the spectrum of disease, not only satisfactory with disease prevention and treatment but actively promoting health level, life quality, harmonious interpersonal relationship, social psychological atmosphere and other health requirements. Bio-psycho-social medical model calls for that the effective treatment on patients should comprehensively focus on patients' requirements.

\section{The development requirement of modern medical education}

Modern medicine is in front of issues such as social socialization, health requirement diversification, population aging, disease spectrum change, new subjects' emerging, and interdisciplinary subject growth [4]. Modern medical education with the characteristic of promoting all human health requires medical students to have superb technological level and the medical humanistic spirit of caring patients and respect life. WHO proposes that "five-star doctors in the 21st century should be health provider, medical decision maker, mental communicator, community leader and organization manager" [5]. Decision-making, communication, leadership, and management during the process requires for humanistic quality education on medical students for cultivation and shaping.

\section{The requirement of professional certification}

"Undergraduate medical education standard-clinical medical specialty" has proposed the most basic requirements from the objective of ideology and morality and occupational quality, knowledge purpose and technical purpose for students' quality and some basic aspects of the specialty education work. Among all, the objective of ideology and morality "observe law and discipline, establish scientific world view, life view and values, Socialist Concept of Honor and Disgrace, love the country, be loyal to people, and would like to devote all his life for the development of the country's health career and human beings' physical and psychological health; cherish life, care for patients, and have a v; regard disease prevention and illness elimination as the life-long responsibility; regard hospice care offering as his own moral responsibility regard citizens' health interest safeguarding as own professional duty; have a awareness of communicating with patients and their families so that they can fully participate and cooperate the treatment plan; value medical ethics issues in occupational activities, and respect patients' privacy and personalities; respect patients' personal belief, understand other's humanistic background and cultural value" and other specific requirements, strengthen the cultivation of medical humanistic quality. 


\section{Requirement of resident doctors' standardized training}

"Guideline views on establishing the system of national resident doctors' standardized training system" has indicated one of "four insistence" to steadfastly insist the foundation of medical humanistic quality education, main contents including that a comprehensive medical accomplishment of medical ethics style, interpersonal communication and medical policies and regulations is one of important connotations of resident doctors' standardized training, as well as the foundation of doctors qualifications to practice physician.

\section{Discussion on the of path medical humanistic quality education}

\section{Establish the educational concept of emphasizing both specialty and humanities}

Medical colleges should penetrate humanistic quality education concept throughout the whole process of talent cultivation. Medical students should integrate "proficiency in skills" with "benevolence". During medical education, colleges must insist the concept of emphasizing both specialty and humanities from cultivation target and course setting, change from stressing professional knowledge and skills to students' comprehensive development, and the balanced development of medical students' professional knowledge skills, communication ability and humanities quality. Medical colleges should cultivate medical talents with good ideology and morality, and professional quality, always with scientific attitude, innovation and critical spirit, teamwork spirit, and well-trained clinical thinking ability, expression and communication ability, awareness and responsibility of respecting patients, and establish solid medical humanistic knowledge and sufficient connotation and humanistic accomplishment while mastering skillful clinical techniques.

\section{Layers of medical students' humanistic quality education course and the system construction}

Medical humanistic quality education course is roughly divided into three layers. The first layer, basic humanistic course, which refers to required courses for universal liberal study not differentiating specialties including "two classes", literature history and philosophy, aesthetics, psychology, and foreign language, etc. The second layer, comprehensive humanities courses which are interdisciplinary subjects with medical science and humanistic social science intersected such as medical ethics, medical sociology, medical psychology, medical law, medical philosophy and other inter-disciplines. The third layer, application practical humanistic courses such as behavioral medicine, doctor-patient communication, and medical insurance, etc. Deepen teaching reform, with all-round development of human being theory in Marxism as guidance, with improving medical students' humanistic quality as the goal, follow the inherent relation and logic between medical humanistic subjects, according to students' mental change, development features, and medical talents' growth rules, combine medical humanistic education with medical professional education in the overall framework of advanced medical education to establish medical humanistic course system [6]. "Undergraduate medical education standard-clinical medical specialty" has set the course into six modules, humanistic courses involving ideological and moral cultivation, behavioral science and humanistic and social science, medical ethics, etc. Reasonably plan humanistic core courses and system, apply practical and closely related to medical practical requirements and cover subject contents of humanistic knowledge, accomplishment and formation, highlight subjects which are produced by humanistic and social science and medical science. According to the humanistic course setting, medical humanistic teaching target, realistic demand, it is necessary to regard medical ethics, health law, medical psychology, doctor-patient communication and medical sociology as the core courses of medical humanities [7]. Proceed other courses by means of elective course, extracurricular seminar and extracurricular academic discussion, etc. Appropriately dig out humanistic materials in professional basic courses, solve course space problem in an integrated thinking, look for the coherence point between medical humanities, basic medicine, and clinical medicine education and explore humanistic education in medical professional courses [8]. Pay attention to the construction of hidden courses, and combine with hidden courses organically to establish comprehensive 
humanistic quality cultivation system so that medical students can transform external humanistic knowledge into their care and respect to patients and develop personalities and behaviors of respecting life and caring for others.

\section{Accelerate construction of teachers' team, conduct continuous teaching and improve the quality of humanistic quality education}

In basic knowledge cultivation stage, to change the single type situation that "teachers majoring in liberal art are poor in medical knowledge and teachers majoring in medicine lack humanistic knowledge", humanistic teachers should conduct transdisciplinary learning, and master basic medicine principles; medicine specialty teachers should expand their humanistic quality and knowledge through reading humanistic books and participating humanities and social science seminars and reading salons; in clinical learning period, clinical doctors should participate humanistic medical licensed skill training, take medical humanistic classes or seminars or discussion and explain legal and ethics issues in social medical hotspots, get medical students early exposed to clinic, focus on cultivating their practical problem solving ability, and complete the role transition from student to doctor so as to adapt to the requirements for medical workers under the new situation.

\section{Combine visible education with implicit education, and focus on actual practice}

Except for giving full play of the visible education effect of humanistic quality education course cluster, it is necessary to combine with implicit education, strengthen school cultural construction such as to carry out medical students' ceremonial education, essay activities with medical ethics and practices as the theme, humanistic knowledge competition, theme speech, and organize students to act as volunteers in hospitals and provide medicare guiding service, and create a humanistic atmosphere in advanced medical colleges so that students can step from school to clinic and society, from theory to practice, and achieve the unity of moral knowledge and practice, arouse medical students' thinking on medical professional spirit and doctors' professionalism, so as to cultivate medical students' sense of responsibility, compassion, and kindness, improve social recognition, service and contribution, and enhance sense of responsibility and sense of mission.

\section{Strengthen management}

From management system, operating mechanism and management effect, it is necessary to give essential guidance and support in fund, classroom, class period and staff training. Perfect management system, establish human-oriented management model and reasonable operating mechanism so that students can feel humanistic atmosphere when under management, promote the value and charm of humanistic spirit, and stimulate medical students to produce strong sense of responsibility and sense of mission, improve quality and lay solid foundation for future patient management, service and social service.

To sum up, the core of humanistic quality is "human oriented". There is a long way to go to strengthen clinical medical humanistic quality education. It requires for step by step throughout the whole process of medical education, and combination of practice with actual exploration to cultivate new type medical talents with equal stress on humanistic quality education and medical professional education.

\section{Acknowledgement}

Project source: Project approval of the 7th batch of Zhengzhou Local Colleges and Universities New Century Educational Reform and Talent Cultivation Project, (ZZJG-A7003, Innovation and practice of five-year clinical medical education specialty talent cultivation mode)

\section{References}

[1] Sun Muyi. Medical Ethics (2nd edition), Beijing: Higher Education Press, 2008.48. 
[2] Song Hanjun, Luo Jiabin. Understanding and countermeasures of higher medical education quality under the situation of mass education, Heilongjiang Medicine and Pharmacy, 2005, 28 (4), pp.38-39.

[3] Wang Jinfan. Doctor-patient Communication, Beijing: People's Medical Publishing House. 2nd edition, August, 2006, pp.37-38.

[4] Hu Yanjun, Xie Xing, Huang Lili. Integrate medical humanistic spirit into clinical medical education, Researches in Medical Education, 2007, 6 (5), pp. 390-391, 412.

[5] Shen Xiumin, Jiang Nengzhi. Construction of medical students' humanistic quality education system, Northwest Medical Education, 2009(3), pp.680-681.

[6] Gao Jicheng. Researches on 21century medical humanistic quality education-take ideological and political education as the research perspective, Changchun: Jilin University, 2009.

[7] Chen Hua, Deng Rui, Tian Dongxia. Survey research on medical humanistic education from a perspective of clinical doctor, Medicine and Philosophy, 2013, 34,12 (A), pp. 75-77,83.

[8] Yan Juan, Wang Hongqi, Lian Jie. Thinking on strengthening medical humanistic quality education, Chinese Journal of Medical Education Research |Chin J Med Edu Res, 2012,11(6), pp.605-607 